\title{
Students' perceptions regarding the third year nursing ethics module at Shifa College of Nursing, Islamabad, Pakistan
}

By

\author{
Farida Himat Khan
}

Thesis presented in partial fulfillment of the requirements for the degree Masters in Philosophy (MPhil) in Health Sciences Education at the University of Stellenbosch

Supervisor: Dr. Sharon Kling, Department of Pediatrics and Child Health Faculty of Medicine \& Health Sciences 


\section{Declaration}

By submitting this thesis electronically, I declare that the entirety of the work contained therein is my own, original work, that I am the sole author thereof (save to the extent explicitly otherwise stated), that reproduction and publication thereof by Stellenbosch University will not infringe any third party rights and that I have not previously in its entirety or in part submitted it for obtaining any qualification.

December 2013

Copyright (C) 2013 Stellenbosch University

All rights reserved 
Students' perceptions regarding the third year nursing ethics module at Shifa College of Nursing, Islamabad, Pakistan

Ms. Farida Himat Khan

Shifa College of Nursing

H-8/4 Pitras Bukhari Road

Islamabad

Pakistan 


\section{Table of contents}

Page

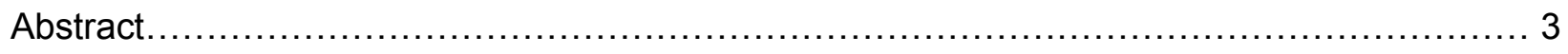

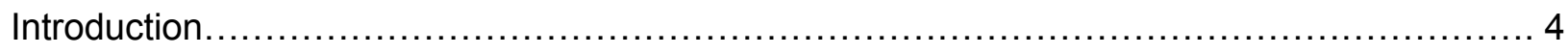

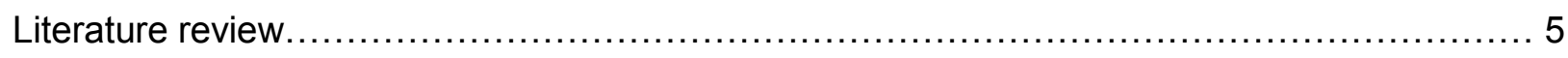

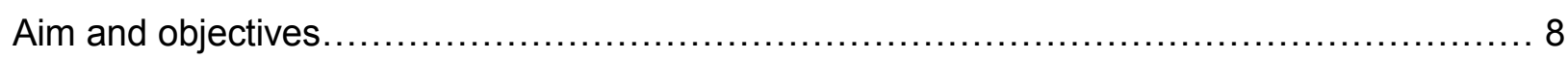

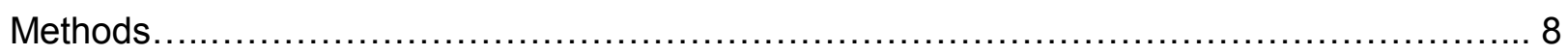

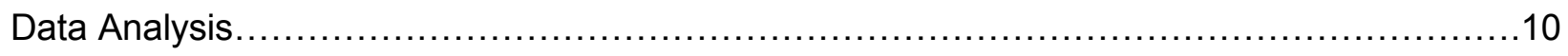

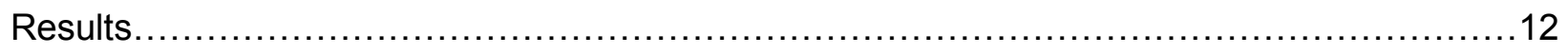

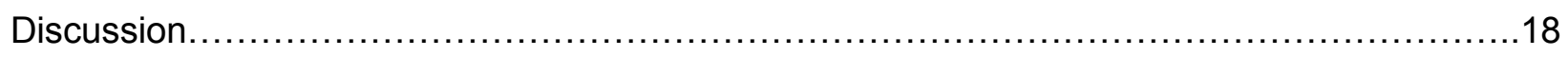

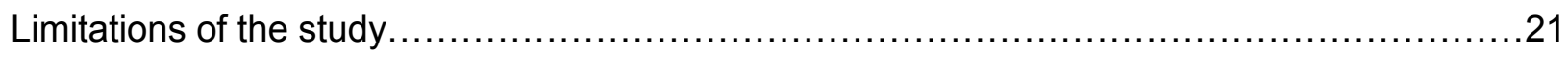

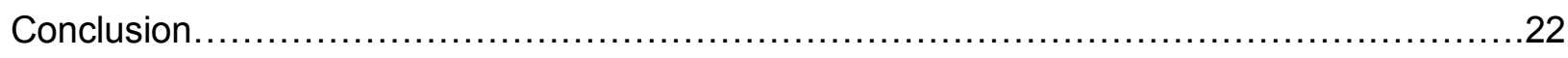

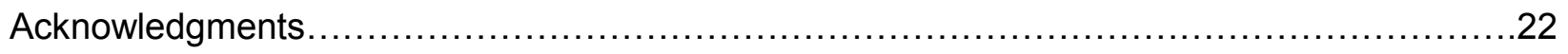

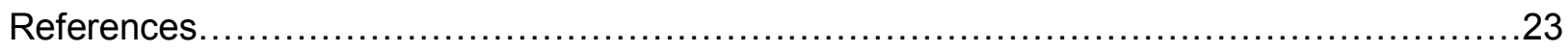

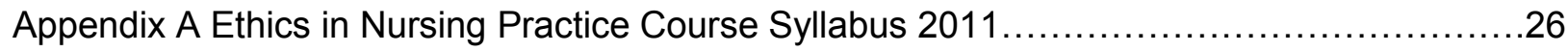

Appendix B Retrospective Pre/Post Questionnaire ..................................29 


\section{Abstract}

Aim: This study aimed to explore the perceptions of third year nursing students regarding the ethics module at Shifa College of Nursing, Islamabad, Pakistan.

Methods: Third year nursing students $(n=26)$ completed a retrospective pre/post survey rating their knowledge before and after the ethics module. Focus group discussions (FGDs) addressed the importance of ethics teaching in nursing, the content, teaching and learning strategies of the module as well as whether the application of the concepts learned in the classroom were practiced in the clinical setting.

Results: Participants rated their knowledge higher in the post-test (4.00) than the pretest questionnaire (2.26) $(p=0.003)$. The main themes identified during the focus group discussions were: understanding their responsibilities towards the patient; an appreciation of the patient as a human being; applicability of the module to the clinical setting; the role of student nurses in ethical decision making in the clinical setting; and the teaching and learning strategies. The context of the nurse's practice was also identified as being important.

Conclusion: The participants valued the ethics module and its applicability to the clinical setting, but changes in the content of the module and the teaching and learning strategies were suggested.

KEY WORDS Teaching ethics, nursing ethics. WORD COUNT 194 


\section{Introduction}

"Ethics is seen as part of a larger plan to develop and enhance the health professional's human values, social conscience, and interpersonal skills" (Coutts 1991, pg. 2). The changing pattern of healthcare and the increasing awareness about health among the patient population compels teaching institutions to prepare their students in such a way that they should be sensitive to the values, beliefs and morals of their patients. Knowledge and skills in ethics for healthcare professionals are as important as they are for the hard sciences, such as biochemistry and technology.

The Pakistan Nursing Council (PNC) in collaboration with the Higher Education Commission of Pakistan (HEC) developed a uniform curriculum for the undergraduate nursing program in 2006. In the curriculum, a separate ethics module is made mandatory for all non-Muslim students and Islamic Studies for Muslim students. The researcher is a member of the PNC inspection team and during visits to different nursing schools and colleges in Pakistan it was evident that, despite the strong recommendations of the PNC and the HEC to teach these courses at undergraduate level, many nursing colleges and universities across the country do not offer these courses as recommended. In these nursing schools and colleges, Islamic Studies is offered to all students regardless of religion. Many nursing schools and colleges do not teach ethics formally. Some incorporate ethics topics such as ethical theories, the principles of biomedical ethics, and nursing history into modules of other subjects. The integration of these topics with other nursing subjects threatens the importance of ethics. Teaching ethics as a course at undergraduate level in Pakistan still needs considerable realization.

The Shifa College of Nursing (SCN) was established in 2004. SCN offers a four year degree program in nursing. Students at SCN are provided with clinical exposure right from year I of the program. Ethics modules are offered in years I and III, respectively. The basic and important concepts, for example responsibility, accountability, truthfulness, and professionalism, are taught to students in year I. More complex concepts such as ethical theories, patient autonomy, informed consent and clinical ethical dilemmas are addressed in year III (the curriculum is attached as Appendix A). This module mainly focuses on applied ethics in nursing practice. It allows the student to critically examine the issues within the framework of ethical principles and theories. It also helps the students to make decisions in the best interests of the patient. Group presentations and reflective 
logs are the only teaching strategies employed in this module. Students' reflective logs and presentations are graded and utilized to assess the students' knowledge gained during the module.

The purpose of this study was to explore the perceptions of third year nursing students regarding the ethics module at SCN. During the literature search the researcher was unable to find a single published study about teaching ethics to undergraduate students of nursing in Pakistan, although the researcher did discover two studies which were carried out about ethics teaching at post diploma level. A bioethics centre was established in Karachi, Pakistan, in 2004. Workshops and seminars are conducted at this centre for students of various universities in Karachi, Pakistan, and these are open to all (Moazam and Jafarey 2010). However, this study appears to be the first study at undergraduate level in Pakistan to explore the perceptions of nursing students regarding the ethics module. The findings from this study add to the limited body of knowledge about the nursing ethics which is being taught in the various colleges of Pakistan. The information obtained from this study could help the researcher to evaluate the ethics module and may enable the nursing faculty members at SCN to implement changes in the module content as well as the teaching / learning strategies for future modules.

\section{Literature Review}

According to Post (2011) "Bioethics is the systematic study of the moral dimensions - including moral vision, decisions, conduct, and policies of the life sciences and healthcare, employing a variety of ethical methodologies in an interdisciplinary setting". Ethics has become an essential component of undergraduate training for health care professionals. The healthcare system is becoming increasingly complicated and complex with changes and the introduction of new technology and treatment modalities. These changes pose a challenge to healthcare institutions to prepare their graduates who are competent not only in scientific knowledge and skills but also in making decisions on ethical grounds (Coutts 1991). Therefore, teaching ethics to health care professionals is as important as the scientific and technical knowledge is in preparing them to manage the patient (Moodley 2007 pg 673).

Forty years ago medical ethics was largely taught through "osmosis" as students observed their teachers in practice. Subsequently, ethics teaching was done using formal lectures in the classroom. In the traditional model of medical ethics teaching the course content includes the theories of ethics, the principles of biomedical ethics (beneficence, non-maleficence, autonomy, 
justice), codes of ethics and selected clinical topics (euthanasia, abortion, end-of-life issues) and the teaching methods combine lectures, small group discussions and selected readings (Fox et al 1995). The emphasis in teaching nursing ethics has shifted from a virtue-based ethics to a dutybased or deontological approach (Park et al 2012). However, it is also recognized that "moral sensitivity" is an important characteristic of a good nurse, and the modern nurse requires ethical decision making and moral reasoning skills (Park et al 2012). Teaching methods for nursing ethics have evolved to include e-learning as well as the traditional lecture room methods, the so-called "blended learning" approach (Hsu 2011).

According to the College of Nurses of Ontario Practice Standards (2009), "Nursing is the therapeutic relationship that enables the client to attain, maintain or regain optimal function by promoting the client's health through assessing, providing care for and treating the client's health condition" (pg 3). It is the quality of the nursing care that adds to the value and respect of the patient. The patient needs to have his feelings noticed and appreciated, which is possible only when the nurse provides care with empathy. If the care is performed in a robotic manner then the potential power of healing is considerably lessened. However, if the patient is cared for with warmth and respected as a human being, then the result will be worth seeing (Dierckx de Casterlé et al 2004).

Nursing curricula were heavily loaded with technical and scientific knowledge in the traditional era with little emphasis on the ethical responsibilities of nurses in the healthcare system. Furthermore, the caring component of nursing, which as the College of Nurses Ontario has stated is the foundation of nursing, was omitted or considered less important in the teaching of ethical behaviors and principles. Nurses do encounter many ethical dilemmas both in hospital and community settings. The cultural and religious values of the nurse and patient are critical aspects of these dilemmas. Therefore, it is crucial that nurses should learn and understand ethics and adopt only those behaviors that are considered acceptable in their profession.

Milton (2004) describes nursing ethics as a subject "that has philosophical underpinnings embedded within the discipline's nursing theoretical perspectives". The purpose of ethics teaching to nurses is to make them aware of the ethical issues encountered in the clinical setting and to enable them to respond to those issues in an ethical way too. (Gorgülü and Dinc 2007). Research has proven that through formal ethics teaching nursing students' "moral reasoning" and capabilities were developed and they were better equipped to respond to ethical issues (Gorgülü 
and Dinc 2007). It has clearly been stated in the research that without formal ethics education, nurses will adopt "unjustifiable and uncritical" ways to make decisions. Therefore, they should be educated and provided with the contemporary models of teaching ethics to make ethical decisions (Kyle 2007; Nasrabadi et al 2009).

Traditionally, ethics teaching was not part of the curriculum, but with the passage of time it became apparent that nurses were not able to make decisions based on ethical principles when problems arose. Therefore, efforts were made to include ethics teaching in the undergraduate nursing curriculum. (Dierckx de Casterlé et al 2004). It is ethics that teaches us to be considerate and show concern for the patient's well being. It is the foremost requirement and forms the basis of nursing care (Bishop and Scudder, 1990; Gastmans et al; 1998). The ethics teaching should not only focus on the teaching of codes of conduct, but should provide a framework of moral reasoning for nurses so that they are able to make decisions when dilemmas and difficult situations arise (Vanlaere and Gastmans 2007).

The Code of Ethics of the Pakistan Nursing Council clearly addresses the responsibilities of nurses and warns them to maintain the standards of the profession through the provision of good quality and ethical care (Pakistan Nursing Council Code of Ethics: Acts \& Regulations 1973 Pg. 2). This Professional Code of Ethics serves for self-evaluation and reflection regarding ethical nursing practice. The code of ethics helps nurses to make decisions based on ethical principles and it also informs the public about nurses' responsibilities and the standards of care (Neumminen 2011). Gaul (as cited by Coutts 1991) examined the effect of a course in nursing ethics on undergraduate nursing students. He found that the students who took the ethics course were able to analyze ethical dilemmas when they encountered them in practice, and he therefore strongly recommended that ethics be included as a course at undergraduate level.

Teaching ethical norms and values is very complex and there is no single best method to teach ethical concepts to students. Researchers have reached divergent conclusions regarding the teaching methodology of ethics education, but the majority of them prefer interactive sessions together with reflections based on the clinical experience over traditional lectures (Nasrabadi et al 2009). Use of case studies, reflections, and real life experiences are cited in the literature as teaching strategies. Educators can utilize a variety of methods to teach ethics, but they need to keep in mind the strategy which enables the students to integrate theory with practice (Woods 2005). 


\section{Aims and Objectives of the Study}

This study aimed to evaluate the current third year ethics module at SCN by exploring the perceptions of third year nursing students regarding the ethics module with respect to the importance of ethics teaching in nursing, the module content, the teaching / learning strategies, and application of the concepts learned in the classroom to practice in the clinical setting.

The specific objectives were:

1. To understand the students' perceptions regarding the contents of the module and the teaching and learning methods used during the ethics module.

2. To evaluate whether the students thought their ethics knowledge had improved after the ethics module.

\section{Methods}

\section{Research design}

This descriptive study used a mixed methods approach, using both a qualitative and a quantitative approach. Through the quantitative method, the researcher was able to explore the participants' perceptions regarding the knowledge they had before the module and information they gained at the end of the module. The qualitative method helped the researcher to explore the participants' perceptions regarding the ethics module content, teaching / learning strategies, the importance of ethics in nursing education, and application of ethics learning in clinical practice. Both the approaches were beneficial to evaluate the ethics module and its impact on students' knowledge and transformation of knowledge into practice.

\section{Sample}

The study sample consisted of third year nursing students at SCN who had just completed their ethics module during the previous semester. The class comprised 26 students. 


\section{Procedures and measures}

The study was conducted between July 2011 and August 2011 at the Shifa College of Nursing, Islamabad, Pakistan. The study was divided into two phases. In the first phase of the study, a self-administered retrospective pre/post questionnaire was circulated among the participants after the completion of the ethics module (Appendix B). The questionnaire included the concepts which students had learned during the ethics module. The questionnaire was pilot tested on 9 (4 females and 5 males) $4^{\text {th }}$ year nursing students who had been through the module the previous year. $\mathrm{A}$ five-point Likert scale was used for responses regarding the knowledge level prior to and after the ethics module, with higher scores indicating better knowledge (1 - very low; 2 - low; 3 - moderate; 4 - high; 5 - very high).

A retrospective pretest-post-test survey is a recognized and validated method to evaluate the perceptions of participants in an educational training environment (Hoogstraten 1982) and to assess the trainees' knowledge, skills or attitudes after completing the program (Colosi and Dunifon 2006). There are advantages to both the traditional pre- then post-test as well as the retrospective pre- post-test. The major advantage of the post- then pretest method is the reduction in "response shift bias" as it allows the learners to reflect on what they have learned in the program (Colosi and Dunifon 2006). The literature supports the use of retrospective pre-/post methods as complete information is collected (Raidl 2004) and the test is easy to administer when there are time limitations (Lamb 2005).

After completing the survey, focus group discussions (FGD) were held with the students. Participants were divided into 3 groups, each comprising about 8-10 students. Participants were divided into FGDs according to their roll numbers assigned to them by the college. In each focus group, there were 2-3 females and 6-7 males. All these FGDs were conducted by one of the Senior Instructors (SI) from SCN who was not involved in teaching these students (none of classroom, skills or clinical teaching). The FGDs were not pilot tested but detailed discussion on all questions was done with the SI before conducting the FGDs. A few of the questions were reformulated or modified after the discussion. The SI used open ended questions to ensure that adequate information regarding the ethics module was obtained. The researcher herself did not conduct the FGDs as she had been involved in ethics teaching to year I students and she is also the Assistant Director at the nursing college. There was therefore concern that the students might not give their opinions and suggestions about the module openly. The FGDs were audio-taped 
and transcribed verbatim. During the discussion, the SI took notes and later her written notes were compared to the audiotape recording. Each FGD lasted for 60-80minutes.

The following questions were discussed during the FGDs:

1. What is the importance of ethics teaching in nursing?

2. How relevant was the content taught during the module?

3. What content do you think should be added to the module?

4. Which teaching strategies were helpful during the module?

5. Which strategies do you think should be added?

6. Who do you think should teach ethics, the subject specialist or any other teacher?

7. How much do you think the ethics teaching is applicable to the clinical setting?

\section{Ethical considerations}

Permission to conduct this study was obtained from the Institutional Review Board (IRB) of Shifa College of Medicine/Nursing and the Health Research Ethics Committee of the Faculty of Health Sciences, Stellenbosch University, South Africa. All students were provided with the information brochure regarding their participation in the study. The students were assigned to the FDGs according to their student numbers, and their identities were protected. They were assured that their privacy, confidentiality and that their anonymity would be maintained while discussing their perceptions/suggestions in curriculum committee meetings. After the students had signed the informed consent form, the self administered questionnaire was distributed to them and their involvement in the FGDs began.

\section{Data analysis}

Data from the self administered questionnaires were entered into and analyzed through Statistical Package for Social Sciences (SPSS) software version 14.0. Descriptive statistics were applied to obtain the frequencies and percentages of the responses. For inferential statistics, the following statistical tests were used:

1. Independent t-test - to determine whether there was a significant difference between the genders; 
2. Paired t-test (non parametric) - to determine whether there was a significant difference among the members of the same group before and after the ethics module. A value of $p<.05$ (95\% confidence interval) was considered statistically significant. This test was chosen rather than the chi-square test as the variables are not independent.

Krueger's Framework Analysis approach was used on the data gathered through the FGDs to minimize subjectivity and bias in analyzing and interpreting, as this approach emphasizes that the analysis should be "systematic, sequential, verifiable, and continuous" (Rabiee 2004 pg. 657). The analysis was carried out manually and no software was used. Firstly, each FGD was labeled as discussion 1, 2 and 3. In each discussion, the participants were identified by the student number allotted to them by the college. The researcher familiarized herself with the data by listening to the recordings several times and read the notes taken by the moderator a number of times. Thereafter themes were identified and, during this step, the researcher started writing down phrases, concepts and ideas. These phrases were shared with the moderator for confirmation and verification. The identified themes were then indexed and the researcher inserted the data under the questions asked of the participants one by one into a Microsoft (MS) Office Word table (MS Office 2003).

The fourth stage is charting. At this stage, all the phrases and themes extracted from the different group discussions were organized and arranged under each theme. The fifth stage is mapping and interpretations. Krueger has proposed seven set criteria as a framework to interpret the coded data under these headings: "words; context; internal consistency; frequency and extensiveness of comments; specificity of comments, intensity of comments; and big ideas" (Rabiee 2004 pg. 658). 


\section{Results}

\section{Retrospective pre- post-test results}

All 26 students participated in the study. The group comprised 7 female and 19 male students whose ages ranged between $20-30$ years.

Table 1 Retrospective pre- post-test mean values (Paired t-test non parametric Wilcoxon)

\begin{tabular}{|c|c|c|c|c|}
\hline Q.\# & How do you rate your knowledge about: & $\begin{array}{c}\text { Before } \\
\text { the } \\
\text { module } \\
\text { (mean) }\end{array}$ & $\begin{array}{l}\text { After the } \\
\text { module } \\
\text { (mean) }\end{array}$ & $\begin{array}{c}P \\
\text { value }\end{array}$ \\
\hline 1 & The main ethical principles and theories & 2.58 & 4.15 & 0.000 \\
\hline 2 & The key concepts and principles of nursing ethics & 2.38 & 3.96 & 0.000 \\
\hline 3 & $\begin{array}{l}\text { Identification of ethical issues as they relate to my practice as } \\
\text { a nurse }\end{array}$ & 2.58 & 4.04 & 0.000 \\
\hline 4 & $\begin{array}{l}\text { Conflicts that may arise in nursing as a result of different } \\
\text { cultural value systems }\end{array}$ & 2.46 & 3.81 & 0.000 \\
\hline 5 & $\begin{array}{l}\text { Identification of different arguments as they apply to ethical } \\
\text { reasoning }\end{array}$ & 2.42 & 3.85 & 0.000 \\
\hline 6 & Concept of "best interests" as it applies to the patient & 2.62 & 3.96 & 0.000 \\
\hline 7 & $\begin{array}{l}\text { How to use case-based reasoning to approach an ethical } \\
\text { problem }\end{array}$ & 2.15 & 3.73 & 0.000 \\
\hline 8 & Ethical issues related to organ donation & 2.00 & 4.04 & 0.000 \\
\hline 9 & The meaning of informed consent in healthcare & 2.19 & 4.12 & 0.000 \\
\hline 10 & Advance directives in the care of terminally ill patients & 2.08 & 4.00 & 0.000 \\
\hline 11 & Diagnosis of brain death in a patient & 1.81 & 4.12 & 0.000 \\
\hline 12 & $\begin{array}{l}\text { The ethical and moral issues around withholding and } \\
\text { withdrawal of life-sustaining treatment }\end{array}$ & 1.92 & 4.23 & 0.000 \\
\hline
\end{tabular}

The data reflected in Table 1 indicate that students perceived the ethics module to have improved their knowledge. The pre- mean scores are lower than that of the post-test mean scores of all questions. 
Table 2 The overall mean pre- and post-test scores of the ethics module

\begin{tabular}{|l|l|c|}
\hline & Mean & $\begin{array}{c}\text { P value of Paired } t \text { test } \\
\text { (overall difference) }\end{array}$ \\
\hline Overall mean pretest scores & 2.26 & 0.003 \\
\hline Overall mean posttest scores & 4.00 & \\
\hline
\end{tabular}

Table 2 depicts the overall mean of the pre- and post-test scores of the ethics module. The Wilcoxon non parametric t-test was applied to calculate the mean difference. The result shows that students improved their overall level of ethics knowledge through the content taught in the third year nursing ethics module.

Both male and female students participated in this study although the males outnumbered the females. There was no significant difference in the perceptions between the mean scores of male and female students according to this test.

\section{Focus group discussions}

The main themes identified through the FGDs pertaining to the students' perceptions were:

a. Understanding their responsibilities towards the patient;

b. Appreciation of patients as human beings;

c. Applicability of the ethics module to the clinical setting; and

d. The role of student nurses in ethical decision making in the clinical setting.

The students' perceptions are discussed under each theme. 


\section{Understanding their responsibilities towards the patient}

Participants found the content taught in the ethics module helpful to understand their responsibilities as student nurses. As one of the participants verbalized,

"We realized that just giving medication is not our responsibility but we have to take care of our patients from all aspects".

The students realized that their duty was not only to administer medications to the patients but also to make sure that the medication given was according to the standards of care in a safe and ethical manner. Sometimes, it becomes very difficult for nurses to fulfill the responsibilities well as they encounter many challenges. Workload, attitude, practices of other health team members, and working environment are but a few of these challenges, which have an impact on nurses trying to fulfill their responsibilities.

The majority of the participants during the FGDs verbalized that they were unsure about their responsibilities in year I. They used to perform every skill as instructed by senior staff nurses without considering how safe they were to perform the skill. One of the participants mentioned,

"In year I, I came across many issues and at that time I did not realize that those were ethically wrong....now I recall all those moments and get embarrassed that how much my practice was unethical in the clinical setting".

Participants saw a positive change in their own practice. They were able to or at least tried to modify their practices in the light of the ethical principles they were taught. 


\section{Appreciation of patients as human beings}

It is evident from the participants' discussion that ethics teaching had a positive impact on the participants' attitude and behavior. They started showing empathy with the patients and thinking about the patients as human beings, having rights, values and being worthy of respect. As one of the participants shared,

"We take care of patients from various backgrounds; each patient has their own values, beliefs and norms. Ethics is a subject which helped us to understand patient values, norms, and religious differences. The module helped to understand patients as human beings".

Participants verbalized that the module helped them to provide care without harming their patients. The researcher's experiences in various teaching hospitals of Pakistan indicate that patients are often used for teaching of nursing students. The teachers and students are so accustomed to performing the physical examination on patients that they do not realize the importance of maintaining the privacy and dignity of the patient while conducting these procedures. Students practice their skills on patients and the patients are not even aware that this is the case, as students do not inform them that they are student nurses carrying out the physical examination. There is no problem in performing skills which they have learnt under faculty supervision, but patients should know and they have the right to know who is examining them. As one of the participants verbalized,

"Well in the beginning of my clinical rotations, I respected my patient's view point .... maintained privacy because of fear of teacher.... but after this module whatever I do it is from my heart, whenever, I talk to my patient, or do any skill I follow the ethical principles".

This module helped them to show respect to the patient and realize the importance of the patients' values and beliefs. 


\section{Applicability of the ethics teaching to the clinical setting}

In the literature, there is a debate as to what content should be added to the ethics module. Participants in this study valued the topics taught during this module and it is evident from the quantitative data results that they gained significant knowledge after taking this module. However, when asked how relevant the content taught during the module was and what content they thought should be added to the module, participants in all the FGDs were of the opinion that some of the topics which were learned in the ethics module should be merged with relevant nursing subjects. For example, topics such as informed consent and disclosure of bad news should be added to the concepts of the Fundamentals of Nursing course which is taught in year I. SCN students are assigned to clinical work from year I and they encounter ethical issues very frequently. Students do not have any idea about the importance of informed consent and they also feel incompetent when their patients are told about their dwindling health. Teaching these concepts together with the appropriate course will help them to relate the theoretical concepts to practice.

Participants appreciated the ethics module as it helped them to identify ethical dilemmas in the clinical setting. Participants found the ethical theories, principles and ethical decision making models relevant, important and applicable to the clinical setting. However, they felt that topics such as "the client's will" and the "patient's bill of rights" are not applicable in the Pakistani context and such topics should be excluded from the module. On the other hand, issues such as organ donation, end of life issues and allocation of scarce resources were frequently encountered. These topics were considered very relevant and well taught in the module.

One of the participants shared an experience he had encountered.

"During Emergency rotation a 24 year old female was brought to the hospital with brain hemorrhage....the patient was not put on ventilator as she was very poor and died after 2 hours. As we were told in the class that every patient has to be treated regardless their financial status. In this case, the poor patient was not provided with the required medical support (ventilator)."

He further added, 
"Although our knowledge regarding the topic is enhanced but we could not see the applicability of that knowledge in the clinical settings".

\section{The role of student nurses in ethical decision making in the clinical setting}

Ethics modules are offered in Year I and Year III of a four year degree program at SCN. Participants were able to explore the ethical issues and identify a positive change in their own behavior and practices during the clinical module after completing this module. Participants, however, found it difficult to resolve the ethical issues in the clinical setting. Participants felt unhappy as one of the outcomes of the ethics module at third year level was to explore, analyze and resolve ethical issues. Participants' frustrations were observable during the FGDs. As one of the participants mentioned,

"Well, so what if we write the incident/reflection.....it was only for us to analyze the situation and come up with recommendations, but what about the wrong which has happened with the patient?"

Despite nurses being taught to be the advocate for the patient, student nurses found that they were unable to advocate for the patients' safety or their rights. According to the participants in this study, the barriers include senior nurses, physicians and even their own clinical teachers who did not encourage them to speak out if they had observed wrong practices being done to their patients.

\section{Teaching strategies}

Participants were asked questions about the teaching and learning strategy employed during the ethics module. Although this did not emerge as a main theme from the FGDs, the participants did share their views on the teaching of the ethics module. It transpired that student-led presentations and the students' reflective logs were the only teaching strategies being used throughout the module. Participants were in favor of utilizing a variety of teaching and learning strategies rather than focusing only on one strategy. Some of the suggestions that were made included small group discussions, film/media and real case-based scenarios.

\section{Discussion}


The nursing profession is evolving continuously with the advancement in technology. The introduction of new technologies has resulted in many challenges and ethical dilemmas for nurses. The roles and responsibilities of nurses have expanded beyond the usual bedside patient care. They are expected to be involved in decisions, which traditionally were not theirs to make. Ethics teaching is very important to sensitize them to patients' needs and clinical ethical problems.

In this study participants perceived the ethics module to be worthwhile and valued the ethics teaching very highly, as they felt the teaching helped them to realize their responsibilities. The results of the quantitative data demonstrate that participants thought that their knowledge had increased after the ethics module. This is evident by the increase in the overall mean score from 2.26 for the module pre-test to 4.00 for the post-test, a significant difference with $p=0.003$. The advantage of the retrospective pre- post-test has been discussed in the methods section of this study. Its major disadvantage is that the students' recall of their pre-ethics module knowledge may have been colored by the intervention (i.e., the ethics module) and may therefore not be accurate. However, one can interpret the results as the students perceiving that their knowledge improved after the ethics module.

The results indicated that the students believed it was important for nurses to have a basic understanding of the various concepts, principles, and theories used in ethics. The advances in technology and the increase in research activities to test different medications are frequently accompanied by breaches in ethical standards. Patients are not aware that certain tests are being performed on them by the consultant for the purpose of research. The result is that nurses who are aware of the ethical principles encounter ethical dilemmas and distress in their everyday practice. Hill (2006) recognizes that most undergraduate students are still in the early stages of their moral development, and the teacher therefore has the responsibility to prepare them to take the charge of their moral development.

Ethics teaching at undergraduate nursing level makes students realize the importance of patients as humans. This is well documented by Vanlaere and Gastmans (2007) who wrote that teaching ethics through "principles of right action" and a "virtue ethics approach" helps nurses to work in a clinical setting in an ethical manner. In a "principles of right action" approach, nurses are familiarized with right and wrong through the implementation of codes of conducts where their responsibilities to the public and patient are defined, whereas the "virtue ethics approach" empowers them to respond to an ethical dilemma according to ethical principles and theories. 
Ethics teaching should instill caring attitudes in students and also help them to respond to unethical situations according to the ethical principles.

Participants in the FGDs seemed unhappy with their roles in clinical settings as they felt they were unable to contribute ethically in these settings. The relevance of ethics in the clinical setting is always an issue for students until they are able to recognize or participate in an ethical dilemma. Bedside ethics teaching and monthly ethics discussion rounds should be introduced into the clinical setting. It is important to involve students in these ethics rounds and in ethics committee meetings to enable them to understand the ethical dilemmas and to engage in formulating possible solutions. The researcher also identified the need to introduce ethics teaching as ongoing professional development for staff and clinical teachers in clinical placements to instill in them the skills to deal with the ethical dilemmas of the patients in their care.

In terms of the content of the ethics module, participants suggested adding topics such as the nurse-patient relationship, nurse-nurse relationship and codes of conduct into the ethics module as they frequently encountered these issues during the clinical rotations. Nurses should understand the relationship they are required to maintain with their clients. They also need to be aware of patients' rights and should behave according to the code of conduct. Therefore, adding these topics to the ethics module would be important to make students aware and allow them to relate to the concepts in clinical settings. The participants felt that topics that are not applicable to the Pakistani context should be excluded from the ethics module. It is important for educators to plan and deliver the content which is contextual and relevant to the local needs of the country, but students also need to understand ethics in its broader context.

The suggestions made by the participants regarding integrating some of the ethics topics into the other nursing subjects are valuable and relevant. It is true that concepts learnt in an integrated fashion are easy to apply, as integration reduces the gap between theory and practice. The researcher is involved in both clinical and classroom teaching, and has observed that students are often unable to integrate the learnt concepts into clinical practice. Thus we need to reduce the gap between bench and practice, but that is only possible through integration of similar concepts. The problem is that many concepts may not be discussed in depth due to insufficient time allotted to the ethics module in our curriculum (one hour class/ week). As Woods (2005) says, even in modern nursing education "nursing ethics may be considered by some to be no more than yet another topic to be slotted into the curriculum, and not as a subject that needs a 
considerable amount of time devoted to it with a well-planned and delivered curriculum" (pg 6). As discussed earlier, the importance of ethics teaching should not be underestimated. Therefore, the ethics curriculum should be planned with care and in-depth knowledge on the topics should be given to the students whether that topic is integrated with other subjects or being taught separately.

There is a debate in the literature about the best way to teach healthcare ethics and it is evident that a wide variety of teaching and learning methods are used (Nilstun et al 2001; Nasrabadi 2009; Hsu 2011). Small group discussions are one of the approaches to engage students actively. During small group discussions students interact with each other and a process to approach the problem is developed whereby the students identify the issues, discuss different options and then come up with the solutions. It is evident from the literature that case studies are being widely used to teach ethics. Case studies provide detailed information about a situation and are an effective method to collect, analyze and appreciate experiences (Pimple 2007). It is also noted by AlJalahma \& Fakhroo (2004) that real cases have proven to be highly useful for students to resolve genuine cases.

Students can watch a movie clip or read the material and then reflect on the problem. Marshall (2003) suggested using film for ethics teaching as it is an "appropriate medium of instruction". Students identify with the characters and their emotions and they feel themselves as part of that movie. This helps the understanding of complex concepts in ethics and also assists students with better analysis of ethical dilemmas and to apply their critical thinking skills.

Reflective logs were found to be the most appealing teaching strategy in this module. Reflective thinking enables the learners to analyze an ethical issue and identify various ways to resolve it.

In the literature, there is a debate as to who should teach health care ethics. During the review of the literature, the researcher found that in various international institutions ethics is taught by nurses, physicians, philosophers, psychologists, and sociologists. At SCN a nurse instructor (with no ethics teaching background) was involved in teaching the ethics module. The participants were adamant that ethics should be taught by people who are experts in the field. Ethics cannot be taught by everyone. The individual should have a sound knowledge of ethics and its concepts so that they would be able to relate the theoretical concepts to excellence in the clinical setting. Unfortunately in countries like Pakistan there are very few subject experts who have achieved a 
master's degree in ethics and have good experience in ethics teaching. With the establishment of a Bioethics Centre in Karachi, Pakistan, people from across the country are now able to enroll in diploma and master's studies in bioethics. Five physicians from Shifa College of Medicine in Islamabad are currently enrolled for master's degrees and diploma level studies at the Centre, and will hopefully be able to contribute to ethics teaching at SCN in the future.

\section{Limitations of the study}

The study sample was representative of only one school of nursing in Pakistan, and the number of students in the class was very small for the quantitative data. Secondly, many nursing colleges and schools across the country do not offer the ethics module as recommended by the PNC and the HEC. These two limitations (the small sample size and the differences in ethics modules) make it difficult to generalize the results to other institutions in Pakistan. The retrospective prepost-test has limitations as discussed above. In addition the ethics module was completed in May 2011 and the study was conducted in July - August 2011. This gap meant that participants might not have been able to accurately recall the attitudes, behaviors and improvement in their knowledge attributed to the ethics module. The findings of this part of the study must therefore be interpreted with caution.

\section{Recommendations}

The content of the undergraduate ethics module should be relevant to the country and context in which the nurse practices and the application of the learnt concepts to clinical practice is also extremely important. The recommendations from this study are to introduce new module content; utilize a subject specialist for the ethics teaching; and employ different teaching and learning strategies, such as debates, movie clips and role plays. Ethics teaching should be compulsory for all nursing students regardless of their religion. 


\section{Conclusion}

This study provided the curriculum committee and higher management of SCN with the opportunity to evaluate the undergraduate nursing ethics module content as well as the teaching/learning strategies employed during the module. The recommendations have been implemented for 2012 and will be evaluated in a future study. The researcher has written a proposal to the PNC to make the ethics module compulsory for all nursing students regardless of their religion.

\section{Acknowledgements}

The researcher wishes to thanks Dr. Sharon Kling, Department of Pediatrics and Child Health, Stellenbosch University, South Africa, for her supervision and advice throughout the study. Also appreciation by the researcher to Ms. Zahra Ladhani, Director of SCN for her endless and continual feedback on the study, Ms. Subia Rasheed (Senior Instructor at SCN) for conducting FGDs, Mr. Shumail Sikander (Instructor at SCN) for quantitative data analysis and Mr. Faisal Aziz (Instructor at SCN) for reviewing the write-ups. The researcher also acknowledges the research participants who so generously gave their time and input in this study. 


\section{References}

Al-Jalahma, M; \& Fakhroo, E. (2004). Teaching Medical Ethics: Implementation and evaluation of a new course during residency training in Bahrain. Educ Health 17(1):62-72.

Bishop, A.H; \& Scudder, J.R. (1990).The Practical, Moral and Personal Sense of Nursing. A Phenomenological Philosophy of Practice. New York: State University of New York Press.

Colosi, L; \& Dunifon, R. (2006). "What's the difference? "Post then pre" \& "pre then post." Cornell Cooperative Extension. New York.

http://www.citra.org/Assets/documents/evaluation Accessed Jan. 12, 2008.

Coutts, M.C. 1991.Teaching Ethics in the Health Care Setting. Scope note 16. National Reference Center for Bioethics Literature. The Joseph and Rose Kennedy Institute of Ethics, Georgetown University. http://bioethics.georgetown.edu/publications/scopenotes/sn16.pdf. Accessed 10 July 2011.

College of Nurses of Ontario Practice Standards: Ethics. www.cno.org/Global/docs/prac/41034Ethics. Accessed 10 July 2011.

Dierckx de Casterlé, B., Grypdonck, M., Cannaerts, N., \& Steeman, E. (2004). Empirical ethics in action: lessons from two empirical studies in nursing ethics. Med Health Care Philos. 7(1):3139.

Fox, E; Arnold, R.M; \& Brody, B. (1995). Medical ethics education: Past, Present and Future. Acad Med 70:761-769.

Gastmans, C; Dierckx de Casterlé, B., Schotsmans, P. (1998). Nursing Considered as Moral Practice: A Philosophical ethical Interpretation of Nursing. Kennedy Instit Ethics J 8(1):43-69.

Gorgülü, R.S; Dinc, L. (2007). Ethics in Turkish nursing education programs. Nursing Ethics. 14(6):741 752 .

Hill, L.A. Exercising moral courage: a developmental agenda. In: Rhode DL (Ed) 2006. Moral Leadership: The Theory and Practice of Power, Judgment, and Policy. San Francisco: JosseyBass.

Hoogstraten J. (1982). The Retrospective Pretest in an Educational Training Context. J Exper Educ 50(4):200-204.

Hsu LL (2011). Blended learning in ethics education: A survey of nursing students. Nursing Ethics 18(3):418-430. 
Kyle, G. (2008). Using anonymized reflection to teach ethics: a pilot study. Nursing Ethics.15(1):616

Lamb, T. (2005). The Retrospective Pretest: An Imperfect but Useful Tool. Evaluation Exchange. 11(2).

Marshall, E.O. (2003). Making the most of a good story: effective use of film as a teaching resource for ethics. Teaching Theology and Religion 6(2):93-98.

Milton, C. L. (2004). Ethics Content in nursing education: Pondering with the possible. Nursing Science Quarterly 17(4): 308-311.

Moazam, F. \& Jafarey, A. (2010)."Indigenizing" Bioethics: The first centre for Bioethics in Pakistan. Cambridge Quarterly Health Care Ethics 19:353-362.

Moodley, K. (2007).Teaching medical ethics to undergraduate students in post-apartheid South Africa, 2003-2006. J Med Ethics. 33(11):673-677.

Nasrabadi, N.A; Joolaee, S; Yekta, Z. P; Bahrani, N; Noghani, F; \& Vydelingum, V. (2009). A new approach for teaching nursing ethics in Iran. Indian J Med Ethics 6(2):85-89.

Neumminen, O., Arend, A.V., \& Kilpi,H, L. (2009). Nursing educators and nursing students' perspectives on teaching codes of ethics. Nursing Ethics. 16(1), 69-82

Nilstun, T; Cuttini, M; \& Saracci, R. (2001). Teaching medical ethics to experienced staff: participants, teachers and method. J Med Ethics 27:409-412.

Pakistan Nursing Council Act and Regulation 1973. www.pnc.org.pk. Accessed December 10, 2010.

Park, M., Kjervik, D., Crandell, J., Oermann, M.H. (2012). The relationship of ethics education to moral sensitivity and moral reasoning skilss of nursing students. Nursing Ethics. 19(4):568-580.

Pimple, K.D. (2007). Using case studies in teaching research ethics. Ethics in Science and Engineering National Clearinghouse Paper 338. http://scholarworks.umass.edu/esence/338. Accessed 10 November 2010.

Post, S.G. Director's letter, Center for Medical Humanities, Compassionate Care, and Bioethics. http://www.stonybrook.edu/bioethics/ Accessed 8 December 2011.

Rabiee, F. (2004). Focus-group interview and data analysis. Proc Nutr Soc 63:655-660.

Raidl, et al. (2004). "Use Retrospective Surveys to Obtain Complete Data Sets and Measure Impact in Extension Programs." Journal of Extension 42 (2) 
Vanlaere, L., \& Gastmans, C. (2007). Ethics in nursing education: Learning to reflect on care practices. Nursing Ethics. 14 (06), 759-766

Woods, M. (2005). Nursing ethics education: are we really delivering the good(s)? Nurs Ethics 12(1):5-18. 


\section{Appendix-A}

\section{Shifa College of Nursing \\ Baccalaureate of Sciences in Nursing Degree Programme \\ Class of 2012 \\ (BSN \& Post-RN BSN)}

\section{Course Syllabus}

$\begin{array}{lll}\text { Title } & : & \text { NHET 315: Ethics in Nursing Practice } \\ \text { Credits } & : & 01 \\ \text { Placement } & : & \text { Year III, Semester I } \\ \text { Day \& time } & : & \text { Friday, 1200-1300 hours } \\ \text { Course Coordinator } & : & \text { Mr. Gideon Victor (GV) } \\ \text { Faculty } & : & \text { Gideon Victor } \\ \text { Prerequisites } & : & \text { Successful completion of year II. } \\ \text { Co-requisite } & : & \text { none }\end{array}$

\section{Course description:}

This course chiefly focus on the ethics applied in the nursing practice. It will allow student to critically examine the issue under the light of ethics. Students will also acquire basic knowledge and skills relating to nursing ethics, general ethics and different life philosophies and develop an awareness of healthcare and its ideological goals from a cross-cultural perspective. It will also help student to make decisions which are in best interest of the patient.

\section{Course objectives:}

The objectives of the course are for the students to learn about the basic ethics applied in the nursing profession.

- Describe nursing and general ethics and life philosophies

- Explain key concepts and principles of nursing ethics

- Identify ethical issues relating to nursing practice

- Appraise an awareness of ethical problems and issues related to nursing

- Appraise an awareness of the conflicts that can be caused by different cultural value systems as regards nursing and treatment

- Criticize to argumentation analysis as regards ethical reasoning

- Propose solution/alternative which are in best interest of the patient

\section{Teaching/Learning Strategies:}

Pre reading, Self study of evidence based literature, case based discussions, case study presentations \& reflective log writing. 


\section{Course expectations:}

1. Punctual in the class

2. Participation in the problem based learning sessions

3. Identify the ethical scenario from the clinical practice and reflect on it.

4. Discuss and finalize the scenario with the faculty for case study presentation

\section{Evaluation criteria:}

- Case Study Presentation /panel discussion/debate

- Reflective log

- Class participation

- Total
$50 \%$

$40 \%$

$10 \%$

$100 \%$

Course Schedule

\begin{tabular}{|c|l|c|l|c|}
\hline $\begin{array}{c}\text { S. } \\
\text { No }\end{array}$ & Dates & Time & Content & Faculty \\
\hline 1 & $\begin{array}{l}\text { Jan, 14 } \\
\text { Friday }\end{array}$ & $1200-1300$ & Ethical principles \& Theories & GV \\
\hline 2 & $\begin{array}{l}\text { Jan, 21 } \\
\text { Friday }\end{array}$ & $1200-1300$ & Moral judgment \& reason for action & GV \\
\hline 3 & $\begin{array}{l}\text { Jan, 28 } \\
\text { Friday }\end{array}$ & $1200-1300$ & Case Based Reasoning & GV \\
\hline 4 & $\begin{array}{l}\text { Feb, 04 } \\
\text { Friday }\end{array}$ & $1200-1300$ & Reflective Log & GV \\
\hline 5 & $\begin{array}{l}\text { Feb, 11 } \\
\text { Friday }\end{array}$ & $1200-1300$ & Decision Making Models & GV \\
\hline 6 & $\begin{array}{l}\text { Feb, 18 } \\
\text { Friday }\end{array}$ & $1200-1300$ & Organ donation & GV \\
\hline 7 & $\begin{array}{l}\text { Feb, 25 } \\
\text { Friday }\end{array}$ & $1200-1300$ & Pregnancy related issues & GV \\
\hline 8 & $\begin{array}{l}\text { March,04 } \\
\text { Friday }\end{array}$ & $1200-1300$ & Reflective Log & GV \\
\hline 9 & $\begin{array}{l}\text { March,11 } \\
\text { Friday }\end{array}$ & $1200-1300$ & Informed Consent & GV \\
\hline 10 & $\begin{array}{l}\text { March,18 } \\
\text { Friday }\end{array}$ & $1200-1300$ & Disclosure & GV \\
\hline 11 & $\begin{array}{l}\text { March } 25 \\
\text { Friday }\end{array}$ & $1200-1300$ & Patient's Bill of Rights & GV \\
\hline 12 & $\begin{array}{l}\text { April, 01 } \\
\text { Friday }\end{array}$ & $1200-1300$ & Reflective Log & GV \\
\hline 13 & $\begin{array}{l}\text { April, 08 } \\
\text { Friday }\end{array}$ & $1200-1300$ & End of life Issues: & Living Will (advance care directive) \\
\hline 14 & $\begin{array}{l}\text { April, 15 } \\
\text { Friday }\end{array}$ & $1200-1300$ & End of life Issues: “Do Not Resuscitate" & GV \\
\hline 15 & $\begin{array}{l}\text { April, 22 } \\
\text { Friday }\end{array}$ & $1200-1300$ & End of life Issues: Brain Death & GV \\
\hline
\end{tabular}




\begin{tabular}{|c|l|c|l|c|}
\hline 16 & $\begin{array}{l}\text { April, } 29 \\
\text { Friday }\end{array}$ & $1200-1300$ & $\begin{array}{l}\text { End of life Issues: Withholding \& withdrawal of life } \\
\text { saving/sustaining support }\end{array}$ & GV \\
\hline 17 & $\begin{array}{l}\text { May, 06 } \\
\text { Friday }\end{array}$ & $1200-1300$ & Reflective Log & GV \\
\hline 18 & & & & \\
\hline
\end{tabular}

\section{Required Readings:}

Burkhardt, A.M. \& Nathaniel, A. K. (1998). Ethics \& Issues in contemporary Nursing. Albany, New York: Delmar publisher.

Husted, G.L. \& Husted, J.H. (1995). Ethical decision making in Nursing. (2nd ed). St. Louis: Mosby.

Bhushan, V., Le, T. \& Wang, K.C. (2002). Clinical Ethics. New York: McGraw- Hill

Erb, G. \& Kozier, B. (1998). Fundamentals of Nursing: concepts process and practice $\left(5^{\text {th }}\right.$ edition). Addison: Welsy. 
Appendix B

\section{RETROSPECTIVE PRETEST: ETHICS IN NURSING PRACTICE YEAR III}

This questionnaire is designed to assess whether this module has met its learning objectives.

\section{Knowledge:}

Please read the statements below and indicate your level of agreement with each statement as it applies to your knowledge before and after the module, using the 5 point Likert scale as follows:

\section{1-very low; 2-low; 3-moderate; 4 high; 5 very high.}

Please circle the appropriate number to indicate your level of knowledge about the following topics before and after completing the module. Please use the following key for rating:

1. Very Low = Don't know anything about this topic.

2. Low $=$ Know very little about this topic

3. Moderate $=$ Know about this topic but there are more things to learn

4. High = Have a good knowledge but there are things to learn

5. Very High = Know almost everything about this topic

\begin{tabular}{|c|c|c|c|c|c|c|c|c|c|c|}
\hline \multirow[b]{2}{*}{$\begin{array}{l}\text { How do you rate } \\
\text { your knowledge } \\
\text { about: }\end{array}$} & \multicolumn{5}{|c|}{ BEFORE THE MODULE } & \multicolumn{5}{|c|}{ AFTER THE MODULE } \\
\hline & $\begin{array}{l}\text { Very } \\
\text { low }\end{array}$ & Low & $\begin{array}{l}\text { Mod } \\
\text { erat } \\
\text { e }\end{array}$ & High & $\begin{array}{l}\text { Very } \\
\text { high }\end{array}$ & $\begin{array}{l}\text { Very } \\
\text { low }\end{array}$ & Low & $\begin{array}{l}\text { Mod } \\
\text { erat } \\
\text { e }\end{array}$ & High & $\begin{array}{l}\text { Very } \\
\text { high }\end{array}$ \\
\hline $\begin{array}{l}\text { The main ethical } \\
\text { principles and } \\
\text { theories }\end{array}$ & 1 & 2 & 3 & 4 & 5 & 1 & 2 & 3 & 4 & 5 \\
\hline $\begin{array}{l}\text { The key concepts } \\
\text { and principles of } \\
\text { nursing ethics }\end{array}$ & 1 & 2 & 3 & 4 & 5 & 1 & 2 & 3 & 4 & 5 \\
\hline $\begin{array}{l}\text { Identification of } \\
\text { ethical issues as } \\
\text { they relate to my } \\
\text { practice as a nurse }\end{array}$ & 1 & 2 & 3 & 4 & 5 & 1 & 2 & 3 & 4 & 5 \\
\hline $\begin{array}{l}\text { Conflicts that may } \\
\text { arise in nursing as a } \\
\text { result of different } \\
\text { cultural value } \\
\text { systems }\end{array}$ & 1 & 2 & 3 & 4 & 5 & 1 & 2 & 3 & 4 & 5 \\
\hline $\begin{array}{l}\text { Identification of } \\
\text { different arguments } \\
\text { as they apply to } \\
\text { ethical reasoning }\end{array}$ & 1 & 2 & 3 & 4 & 5 & 1 & 2 & 3 & 4 & 5 \\
\hline $\begin{array}{l}\text { Concept of "best } \\
\text { interests" as it } \\
\text { applies to the patient }\end{array}$ & 1 & 2 & 3 & 4 & 5 & 1 & 2 & 3 & 4 & 5 \\
\hline $\begin{array}{l}\text { How to use case- } \\
\text { based reasoning to }\end{array}$ & 1 & 2 & 3 & 4 & 5 & 1 & 2 & 3 & 4 & 5 \\
\hline
\end{tabular}




\begin{tabular}{|l|l|l|l|l|l|l|l|l|l|l|}
\hline $\begin{array}{l}\text { approach an ethical } \\
\text { problem }\end{array}$ & & & & & & & & & & \\
\hline $\begin{array}{l}\text { Ethical issues } \\
\text { related to organ } \\
\text { donation }\end{array}$ & 1 & 2 & 3 & 4 & 5 & 1 & 2 & 3 & 4 & 5 \\
\hline $\begin{array}{l}\text { The meaning of } \\
\text { informed consent in } \\
\text { healthcare }\end{array}$ & 1 & 2 & 3 & 4 & 5 & 1 & 2 & 3 & 4 & 5 \\
\hline $\begin{array}{l}\text { Advance directives } \\
\text { in the care of } \\
\text { terminally ill patients }\end{array}$ & 1 & 2 & 3 & 4 & 5 & 1 & 2 & 3 & 4 & 5 \\
\hline $\begin{array}{l}\text { Diagnosis of brain } \\
\text { death in a patient }\end{array}$ & 1 & 2 & 3 & 4 & 5 & 1 & 2 & 3 & 4 & 5 \\
\hline $\begin{array}{l}\text { The ethical and } \\
\text { moral issues around } \\
\text { withholding and } \\
\text { withdrawal of life- } \\
\text { sustaining treatment }\end{array}$ & 1 & 2 & 3 & 4 & 5 & 1 & 2 & 3 & 4 & 5 \\
\hline
\end{tabular}

